\title{
A Conversation with Francisco Gomes de Matos About a Historical Milestone in the Teaching of Portuguese in the United States ${ }^{1}$
}

\section{José Marcelo Freitas de Luna}

Universidade do Vale do Itajaí

Francisco Gomes de Matos is considered one of the most productive Brazilian linguists. His involvement in the area of Portuguese as a Foreign Language, in particular, is recognized not only in Brazil but also in the United States.

From 1957 to 1969, Professor Gomes de Matos taught Portuguese to employees of the USAID in the city of Recife, in Pernambuco. At that time, he used the teaching material of the Foreign Service Institute, in Washington D.C. The material was called Spoken Portuguese, an American creation with a structuralist base, but with a cultural focus as well.

Gomes de Matos earned his master's in Applied Linguistics in the United States at the end of the 1950s. During his time at the University of Michigan in Ann Arbor, he taught Portuguese classes at the university's English Language Institute to professors who were going to work in Brazil.

Professor Gomes de Matos also coordinated and co-authored Português do Brasil para Estrangeiros: Conversação, Cultura e Criatividade, and was one of the creators of the CELPE-Brazil Exam and the Portuguese as a Foreign Language Program (PFL) at the Federal University of Pernambuco. What could be described as the third phase of his activity in the area of PFL is also associated with the United States. In order to work on the project / book of the Modern Language Association for the teaching of Portuguese, Modern Portuguese, coordinated by Professor Fred Ellison, he spent the month of June 1966 in Austin, at the University of Texas. 
We spoke with Francisco Gomes de Matos, at the Headquarters of the Brazil America Association in Recife, on June 22nd, 2010, about Modern Portuguese. As the co-author of this landmark text in the teaching of Portuguese in the United States, among so many other activities that he undertook in the field of Applied Linguistics, Professor Gomes de Matos has a great deal to say about PFL.

In fact, his participation in the project of the Modern Language Association occurs precisely because of his renown-already recognized at the start of the 1960s-for his competent and dedicated work as a researcher in the field of foreign languages and PFL, in Brazil and abroad. These experiences, communicated in major events and journals in the area of language teaching, led Francisco Gomes de Matos to establish contact with the most distinguished linguists in the world. And so it was that he was invited by Professor Fred Ellison to form part of the group that planned and executed Modern Portuguese.

In that same year, 1966, several months after the inauguration of the Applied Linguistics Centre of Yázigi in São Paulo, of which he was the founder and director, Gomes de Matos assumed his important position in the group. He would later contribute to the scientific description of spoken Portuguese in Brazil, the object of the book, with visual aspects of the audio-lingual approach, especially visualized dialogues, and would help coordinate many of the project's activities in Brazil.

Professor Gomes de Matos's statements relate to his essential involvement in the Modern Portuguese Project. With a wealth of relevant details on the contributions of renowned professionals, such as Mattoso Câmara and Rachel de Queiroz, he reveals to us the climate of opinion at the time the project was conceived, formulated and developed. By exploring this context, we are able to safeguard, for our own and future generations, the accumulated knowledge of language and of the pedagogical and linguistic practice of PFL.

José Marcelo Freitas de Luna: Describe your time as a PFL teacher and researcher. How did it all begin?

Francisco Gomes de Matos: Well, my activity in the area of Portuguese as a Foreign Language (PFL) began in the 1950s. In fact, at that time, here in Recife, 
there was a need for Portuguese classes for Americans who worked for USAID, and the material available was the first challenge, what material to use with these Americans who were based here. The material was provided by the General Consulate of the United States in Rio de Janeiro. It came from Washington. It was called Spoken Portuguese. It was the FSI textbook, known as the teaching material produced by the Foreign Service Institute. I met the person who wrote this material, Dorothy Rauscher. She was one of the Americans who dedicated themselves to learning the Portuguese language perfectly, and it's surprising that in the beginning, in the early initiatives in teaching Portuguese to Americans who lived here, the material was produced in the United States. Those folders arrived, with their loose-leaf pages, and we used the material. This reminds me that a pioneering event in the history of Portuguese language teaching for English speakers was the creation, in the 1940s, at the start of the Second World War, of the textbook Spoken Portuguese, as part of a program called the Army Specialized Training Program. It was at the time of the rise of structural linguistics; top linguists were invited to create their textbooks for Spoken Spanish, Spoken French, Spoken German, Spoken Turkish.

JMFL: For the Americans?

FGM: For the American military personnel. As for Portuguese, the material was created not by a Brazilian, but by an American of Italian origin. Spoken Portuguese was created by Vicenzo Cioffari, who was an attaché in the General Consulate of the United States in Rio de Janeiro. He was very fluent in Portuguese and, apparently, he had some knowledge of linguistics. He spoke fluently, almost without a foreign accent, and at that time, there were no Brazilian linguists available. Mattoso Câmara could have been considered for the job, but Mattoso was at Columbia University at the time and was not active in the area of PFL. So they asked Vicenzzo Cioffari, and that was how Spoken Portuguese came about. It is one of the pioneering books, hence the North American contribution in the early days of the teaching of Portuguese as a Foreign Language.

JMFL: I see. How did your relationship with Professor Hensey, Professor Ellison and the University of Texas at Austin come about? 
FGM: This really is a phase in my academic life that I love to talk about, because it's very dear to my heart. How did I first come to know about the Portuguese Language Development Group project? In the 1960s, I moved to São Paulo. I was corresponding with colleagues who taught Portuguese as a Foreign Language in the United States, and through this correspondence, I learned about Henry Hoge of Florida State University, who had published some material for teaching Portuguese. The book was entitled Oral Brazilian Portuguese. And Henry Hoge, in presenting this project, optimistically referred to the development of studies of the Portuguese language in the United States. Immediately, through this correspondence with Henry Hoge, I learned that in Austin, at the University of Texas, was one of the bastions of Portuguese teaching in the United States: Fred Ellison, who had received his PhD in California, in Los Angeles. He had translated books by Rachel de Queiroz, he was her most appreciated translator, and he was a great promoter of the Portuguese language at the University of Texas-Austin. So I wrote to Fred to introduce myself. This was in 1966. In February, I had been to Montevideo, for the InterAmerican Institute of Linguistics. In Montevideo, there was an invitation from the language school Yázigi for me to move to São Paulo, to become director of the Centro de Linguística Aplicada, with the support of the Ford Foundation. I had already written to Fred Ellison, having made the initial contact with him by letter, and he said that actually he was thinking of submitting a project to the Modern Language Association to try and get funding to continue the Modern Language Association Textbook Projects. Fred had already published two more informative articles about the project. So he said to me, I know you are there at Yázigi, your work focuses on the production of teaching materials, and Yázigi already has a small book on Portuguese as a Foreign Language. He asked if I would like to join the group. I was interested but wanted to know more about that opportunity.

JMFL: This was in 1965?

FGM: In 1966, at the beginning of 1966. I told him "I've just moved to São Paulo, but I'm very interested in this project, because one of the missions of 
Yázigi is to promote Portuguese for foreigners". So then Fred said, "look, Rachel de Queiroz is the main author of the dialogues and readings and the essays, and you would be a co-author and linguistic consultant." At that time, there weren't any descriptions of spoken Brazilian Portuguese. The non-existence, or near non-existence of texts and descriptions of Portuguese led me to accept, and I said, "look, how long would I have to stay in Austin?" So we negotiated, and it was decided that I would stay one month, July, during the vacation. I took my vacation, and this is how the opportunity arose to go to Austin and meet the other members of the team: Fritz Hensey, who is a sociolinguist; Richard Barrutia, a linguist who worked in Irvine, also a Spanish and Portuguese teacher; James Wyatt, who at that time was taking the first steps in computational linguistics. He was probably the pioneer in the production of the first computerized vocabulary list for a textbook of Portuguese as a Foreign Language. It was the first textbook to have its lexical component analyzed by computer. That was the work of James Wyatt. As he had this technological background, that was the task he was given. And so we all got together in Austin. There was Fred Ellison, who had an excellent background in Brazilian literature, but he had broader vision, and keen organizational leadership. And so he gathered the team. Fred, Fritz Hensey, Richard Barrutia, James Wyatt, Henry Hoge and me. And we created the trial edition.

JMFL: Rachel had already sent her texts?

FGM: Rachel, being unable to travel to Austin, sent the texts to Fred. Her contribution was twenty cultural dialogues and twenty essays. Each cultural dialogue was the point of departure for a unit, as the plan was for the book to have twenty units. She suggested the characters, and thought up the idea of an American girl studying at PUC-Rio de Janeiro. Her name was Patricia, an exchange student. Many of the dialogues were set in Rio de Janeiro as well, a city that Rachel and Fred were very familiar with.

JMFL: The discussions about the dialogues, between Rachel and the group, were they mostly between Ellison and Rachel? 
FGM: Yes. We never communicated with each other directly. I only talked to Rachel years later, when I met her here in Recife for the Congresso de Literatura Nordestina (Literature Congress of the Northeast).

JMFL: And Mattoso Câmara’s support as a consultant?

FGM: Mattoso Câmara, his daughter Lúcia Câmara, an anthropologist and others were consulted regarding the selection of linguistic structures. It was an important task, as, at that time, there were no descriptions of Brazilian Portuguese applicable to language teaching. Even today I ask myself: what constructions should be given priority in the teaching of Portuguese to students identified as advanced? The question still remains unanswered. Portuguese grammar has some complex constructions. Ataliba Grammar Nova Gramática do Português (2010) identifies syntactically complex structures, but from a didactic point of view, it is more intuitive, and even today, it deserves serious study and discussion, so that we can reach if not a consensus, at least common sense. When selecting grammatical contents for advanced students, what do we mean by advanced? Syntactically advanced? Lexicopragmatically advanced? The consultations made with Mattoso Câmara were few, but they were consultations that had more to do with the choices of regional varieties and syntactical variants.

JMFL: Did he ever travel to Austin to see you and the team personally?

FGM: No, no. Fred Ellison was in Rio, and he discussed it with Mattoso. Lucia Câmara also helped with this in order to reach a decision about which varieties to present in Modern Portuguese. The decision was interesting, because at that time, "carioca" (native accent of Rio de Janeiro) was still prevalent, so the Portuguese spoken in Rio de Janeiro had to be well represented. What additional varieties of Portuguese would be represented in the textbook? As a linguistic consultant and co-author, I also gave my opinion, but they listened to Mattoso, they listened to various people and then reached consensus. When creating the characters, Rachel gave them a regional, geolinguistic distribution. One character was American, Patricia; there was a character from Rio de Janeiro, one from 
São Paulo, one from Minas Gerais and one from Pernambuco. Why? To ensure that the Northeast was linguistically represented. From the point of view of linguistic democracy, respect for the linguistic diversity of Brazilian Portuguese was well established. Rachel's essays were recorded by a radio announcer with a São Paulo accent. So there was a narrator, who recorded the readings in a São Paulo accent, characters from Rio de Janeiro, Minas Gerais, Pernambuco, São Paulo, and the American. From the point of view of geographical variation, we had a lot to offer in the book.

JMFL: From the point of view of the variety of Brazilian Portuguese, at that time, did you and your colleagues seek to complement European Portuguese with Modern Portuguese? Was this one of your concerns?

FGM: Yes, it was. At that time, the teaching of the European variety was predominant. There were the Institutes funded by the Portuguese Government, and most of the readerships were held by Portuguese readers. Brazilian involvement, through diplomatic channels, was minimal. So it was time to start promoting the identity of Brazilian Portuguese. Although I wanted to question the title, Modern Portuguese, in English, it was difficult because the Modern Language Association said: we want to have the title of the book in English. I did question it, but I was voted out, because the MLA had already imposed the adjective "modern" before Spanish, and now it insisted on Modern Portuguese. Just as the MLA insisted on maintaining Modern Spanish and the words modern or contemporary didn't even appear in Spanish on that book's cover, there could be no words in Portuguese on our textbook cover. There are institutional reasons for that, part of the history of the Modern Language project. But in this regard, we felt that it was a strategic moment to launch a new textbook, to start building an image of Brazilian Portuguese teaching materials created specifically for North American universities. If you look in the introductory part of the book, you will see the commitment of many universities that supported the project, because they saw it as a good time to nurture a favorable climate for the development of studies of the Portuguese language, through Brazilian Portuguese, in the United States. 
JMFL: In what way do you believe that the development of applied linguistics in the United States contributes to the application of the principle of variations and of other linguistic characteristics to be explored from a didactic point of view?

FGM: In mentioning these facts related to the creation and testing of Modern Portuguese, they are closely linked to the development of applied linguistics in the United States, because in our group, Richard Barrutia was working in Spanish and Portuguese, and Fritz Hensey, in sociolinguistics and Portuguese language variation. He was the sociolinguist of the group, who had studied variation on the border of Brazil and Uruguay, and James Wyatt, who had worked in what would be the beginnings of computational linguistics applied to language teaching, was also working with us. Henry Hoge, who had contributed to the production of material on spoken Portuguese with Oral Brazilian Portuguese. The only member of the team who did not have a background in linguistics was Fred Ellison, but he was the great catalyzer and the one who had the idea to invite Rachel, because we wanted the book to have linguistic representativeness and literary credibility. In short, the purpose of the book was to present spoken Portuguese, written Portuguese, Portuguese language essays, and literary Portuguese, and so the project found the ideal person in Rachel. We were very happy with this choice. It is perhaps the only case of a Brazilian writer becoming involved in a Portuguese teaching project for a North American university setting; maybe she is still the only one that has done this, and she also helped write the cultural comments. When we designed the book, Fred said that the cultural component was very important, there were cultural comments written in English for each unit, up to unit ten, and from then on, the comments were in Portuguese for additional exposure to written Portuguese. And he consulted Rachel to write these comments, because we wanted the reader to be aware, for example, about the difference between "nós" and the "a gente" (two variant forms for "we"). At that time, as the consultant in charge of the selection or validation of the constructions to be practiced in the exercises, I told Fred what I thought. I told him that our personal pronoun system had "a gente" besides "nós". It may have been the first book of Portuguese as a foreign language to introduce "a gente." It appears in Rachel's dialogues. We had to move forward. On one occasion, in 1976, Evanildo Bechara was editor 
of the Revista Littera journal, for teachers of Portuguese, and he said, don't you want to contribute and send us something? I said I wanted to inventory the constructions of spoken Portuguese that could be considered for inclusion in a textbook. So at that time, I wrote this article for Littera, entitled "Usos do Português Oral, uma lista de referência" (Uses of Oral Portuguese, a Reference List) which had been drafted, in fact, before the Modern Portuguese project, because Yázigi already had Português para Estrangeiros, and one of the first challenges they proposed to me in São Paulo was [to decide] what structures we needed to use and why. So I sent it and Bechara published it, perhaps it was the first list of syntactic usage variants, the usage variants that we should consider, and which ones to select for a textbook of Portuguese. This preliminary list was very useful as a kind of control, because it was strikingly convincing in the dialogue I had with my colleagues, because they said, "but why you believe that this construction should be introduced?" I said, "because it occurs in Portuguese and it is distinctive in Portuguese". This was the case, for example, with the contrast between "está quente aqui hoje" (It’s hot here today) and the more emphatic "está é quente aqui hoje" (It is hot here today!). I persuaded the group to include uses that today, with the data we have from Corpus Linguistics, can be demonstrated through levels of frequency. So my list drawn up before the Littera article was essential, and enabled me to debate with the team, because I was the only Brazilian, and they saw me as a user-consultant with full powers, to say, "this is authentic" or "this is not authentic". I had to analyze each exercise and say this is more "Spanglish," "this one here doesn't sound natural"; to give my opinion on whether the constructions sounded natural or appropriate. And for this Applied Linguistics was very useful to me, together with the fact that colleagues were also working in Applied Linguistics, particularly Barrutia and Fritz Hensey, since each of them had their area of expertise and vision of Portuguese.

JMFL: Also in relation to this confirmed relationship between Applied Linguistics and the promotion and development of the project, from which Modern Portuguese was derived... in your opinion, were there predecessors, of teachers, researchers of Portuguese as a foreign language in other centers of the United States, thinking and working in this area, before the Modern Portuguese project? 
FGM: I'd say at the same time, because Georgetown University-based Maria Isabel Abreu and Cléa Rameh published Português Contemporâneo in the same year, 1966, as we designed, conceived and wrote the trial edition of Modern Portuguese. Unlike other books, MLA required a trial edition, which could be tested in universities. This gave the book a degree of reliability.

JMFL: Did you ever talk with them? Were you aware they were producing in the same area?

FGM: We knew, but there was no dialogue between us at that time. I was aware of it, but as the edition met the requirements of Georgetown and that region, it wasn't so easy to interact as it is today. Before them was Hoge, with Oral Brazilian Portuguese, published in Wisconsin, which was one of the great centers of Portuguese teaching. That was where Henry Hoge, author of Oral Brazilian Portuguese worked. So we knew about these initiatives.

JMFL: Were they taking place at the same time?

FGM: They were, but at that time we didn't have the culture we do now of interacting that is so intense today. We did not communicate as easily as we had decided, for example, what structures to include in Modern Portuguese, because we knew that many students who would use this book had already learned some Spanish. It was a distinguishing feature, because it was to be used by beginners, but if you examine Rachel's essays, which are very long, you see that at that time, the target public consisted primarily of American students of Spanish who could make the transition to Portuguese.

JMFL: So for this, the fact of being in Texas, and in a Department of Spanish and Portuguese, is inspiring, isn't it?

FGM: It is, hence the need to offer a small contrastive summary of Portuguese and Spanish. And we did not have, on the team, anyone who worked specifically in this area. So we invited David Feldman from California State University 
at Fullerton. He wrote the summary, which was included in the Instructor's Manual. To gain a proper knowledge of the student's book, you first need to analyze the manual, because it contains some essential elements of the book that were the result of research. The statistical analysis of the vocabulary is in there, the written scripts for the illustrator of the visualized dialogues were included in the manual, something that was completely new, even today this is not done. As, for instance, how the illustrator would show the characters drinking coffee in a cafe. I wrote the scripts, I'd worked on television in the United States, I had done educational television, when I studied in Michigan in 1959 and 1960 I took educational television as an elective, and I wondered if one day I'd be able to use this knowledge. I never imagined that in 1966, I would need it, because when we decided to do the visualized dialogues, to hire an artist, when there was bidding for the American publishers to publish the commercial edition, then, at the same time, the illustrator would be selected and hired. So, the illustrator asked how he would do the illustrations, from a pedagogical point of view. I said, I'm going to do the script, this script is in the Instructor's Manual, which you can see is so detailed that some even said all that was left was for the characters to actually speak: it was a sample of Brazilian culture's visual language. The characters are described there, the visual language, and this Fred Ellison said would be very useful for the American teacher, especially the treatment of gestures, so that people could see the characters in visual action.

JMFL: You said just now that, although you knew about the work that other teachers and researchers were doing in other regions of the United States, there was no communication, or dialogue?

FGM: Very little, I mean Henry Hoge talked with Barrutia and with Fritz, probably. They wrote to each other, they knew one another, given that they were both working in similar areas. I myself met with Maria Isabel Abreu, on my return to Michigan, I spent just over a month in Georgetown, when Robert Lado moved from Michigan to Georgetown, I met her briefly. At that time there was still no Modern Portuguese project. But Maria Isabel Abreu is among the people who were consulted, by Fred, certainly, about the initial design. I believe there was interaction between them. To me there was no point doing the consultation 
officially, but I think Fred managed to write to them and ask, if not for suggestions, for their support, basically, as they were pioneers, living over there, Brazilians who were creating material. Because there were also American authors, who had created materials for Portuguese, and Brazilian authors based there who were creating material too.

JMFL: Based on their experience of teaching Portuguese?

FGM: Exactly. For example, for grammars, you have The Syntax of Spoken Brazilian Portuguese (1969), by Earl Thomas, who was one of the great pioneers in the description of contemporary Portuguese, published in Vanderbilt.

JMFL: You spoke just now about the role of Ellison, even referring to him as a catalyzer. In your view, was he the leader?

FGM: Yes, he was. He was a leader, he was the Project Coordinator, so much so that when the MLA authorized the project, it was submitted by him. In the book, he was named the organizer. I appear as the Coordinator of audiovisual materials, because this was precisely my experience in São Paulo. Fred was the coordinator of the project, so he was responsible for selecting the authors and collaborators, as in the case of David Feldman, who was brought in as the writer of the contrastive grammar sketch of Spanish and Portuguese. He was the coordinator, the idealizer, he and Hoge. They knew each other, and Hoge's work was what gave the inspiration for the project, as he had written Oral Brazilian Portuguese. Ellison was the coordinator. Besides the meeting in Austin, he also called a meeting in Mexico, with me and Hugh Treadwell, the editor from Knopf. There, we continued the discussions that had begun in Austin. Fred is the mentor of all this, an outstanding leader in this project.

JMFL: When you met for the first time, you spoke about the care with variations, oral, writing, the representativeness of various forms of oral and written manifestation of the varieties of Brazilian Portuguese, and you clarified that there was this concern with the functionality of the language that is also 
manifested in the organization of a curriculum that seems to me to be both more functional and communicative?

FGM: Exactly, in a certain way, although in 1966 the strongly structuralist approach was still prevalent, in practice, three of us had classroom experience and we were functionalists, in our approaches and techniques. So, when planning exercises that were strongly structural, and which exercised a certain control in the use of Portuguese, we on the other hand wanted to give the student what has been called, since the mid 70s, communicative competence. So we created activities, and for this I took advantage of the experience at Yázigi, especially during the trial uses of Modern Portuguese from 1966 to 1968. Six years after the publication of Modern Portuguese, I would contribute to a new textbook for use in Yazigi schools. It was the material subtitled "conversação, cultura e criatividade" (conversation, culture and creativity). The Yázigi material, which I co-authored and planned for Yázigi, which came out in 1977, Português do Brasil para Estrangeiros. I imagined a learning experience based on these three pillars... conversation, creative skills, and culture. It had to have a cultural component and it had to have creativity. They were precisely the more spontaneous uses, and of course, with that vision of functionality. Why was that? At that time, we never considered systematic phraseological studies, which are developing today, particularly in Europe, the Belgians are doing a lot of work in this area. We didn't have the insight into this, and the signs were already there, almost serving to balance the semi-controlled structural exercises, which also gave the user the freedom to exercise options and create, the right for learners to exercise their linguistic creativity, which is a principle that has heavily influenced the creation of didactic material and which recognizes the user's autonomy; his right to use languages creatively.

JMFL: Is your assessment of the material published up to that point the same? I mean, was there the same concern with the functionality of the language?

FGM: It was beginning. I think so. In fact, my PhD dissertation in São Paulo, in 1973, analyzed the influence of the principles of linguistics in manuals for teachers of English as a foreign language in fifteen countries. So I had an initial 
perception of what was going on. I had also studied with Halliday at the Linguistic Institute of the Linguistic Society of America, at Indiana University, in the American summer of 1964, when I began to realize the practical potential of the Hallidayan approach, particularly the key concept of register.

JMFL: Did the dissertation deal with English language teaching materials?

FGM: Yes, it focused on English, and at that time I corresponded with textbook authors of the time to complement what I had found in the bibliography. In my PUC dissertation I stated the principles as being the principles of linguistics characterizing that period, whether there was consensus or not about my formulation. I wanted to link principles to possible applications. For example, the principle of variation is strikingly clear for us linguists-variation and change, two major principles-but then there's the social nature of language, the socio-cultural nature, the systematic nature of language. Only years later would I begin to question my list of principles. I saw a gap in the literature of linguistics on the cognitive nature of language. And shortly afterwards, the humanizing and dehumanizing nature of language, these two dimensions came afterwards. But it's curious, because although in Modern Portuguese we couldn't do this, we never even imagined this in 1971, I mean, the revision of Modern Portuguese was done in 1969, in 1970 an edition was prepared to be submitted to the publishers for the financial bidding, and it was not until six years later that I imagined exercises of the communicative empathy type, dialoguing with such and such person here and facing three lexicogrammatical alternatives, which would be the most empathic? This was introduced at Yázigi, these innovations came after Modern Portuguese. But at that time the approach used could be called structural-cognitive-intercultural, because it brought out the intracultural dimension between the most visible Brazilian culture and the student's American culture. The cultural comments reveal the interculturality of the time.

JMFL: When you met in Austin, did there seem to be any disagreement, or was there total agreement on which approach to use? And also, how did the MLA influence this approach to the book Modern Portuguese? 
FGM: Yes, there were disagreements. Often, with the experiences of each one, particularly those who had already taught Portuguese, one would say, "look, this here is important for American students." And I gave my views too, because I'd had American students, but in another context, not in the university. I had taught Portuguese to American USAID employees, for whom Portuguese was almost like a second language, working here in Recife. While three of the Modern Portuguese authors had been teaching-Fritz, Hoge, and James -well, they taught Portuguese in the university context, and sometimes, they argued, "Look, here in our experience it's important to emphasize..." I'd say, "Do you really think so?" We discussed and met halfway, particularly in the grammatical descriptions, in the grammatical comments. Sometimes things were more detailed, then Fred would say, we are going to put this here in the appendix of the book, so that if the student needs this additional grammatical explanation, information will be provided.

JMFL: And about the MLA?

FGM: MLA gave us full freedom of choice, it only said to recognize the important legacy of Modern Spanish, not that we looked only at Modern Spanish, but Modern Spanish was the product of linguists of great practical and pragmatic vision like Bolinger, for example. So we used insights from it. I knew Modern Spanish very well, and I thought that some things in it were inspiring, particularly with regard to variation and the emphasis on spoken language, which was pedagogically treated in a more realistic way. Although we recognized that there were exaggerations to formulating the principle of emphasis on spoken language, we decided we would not only point out the values of oral uses, but that of written uses as well. So we tried to weigh and balance these decisions.

JMFL: And what's your opinion of the reception of the project, and in particular, the book, by North American university institutions?

FGM: The approach in some ways was provocative, innovative, as for instance the visualized dialogues, where we wanted, besides cultural awareness provided 
by Rachel's dialogues, to get the students engaged in more day-to-day situations, hence my most provocative contribution which led to its being well accepted: Mini-dialogues of four lines, presented with visual support, in an audiovisual tradition, which I accompanied, because I was linked to the AIMAV-International Association of Research on Audio-Visual Methods-and something that has always attracted me is how dialogues can be presented visually, how this can be representative of the culture and help in the assimilation of these dialogues, the phraseologies, for example greetings, how to express sincerity, friendship, cordiality or agreement, disagreement, the setting in which these dialogues take place, and how they reflect Brazilian culture. So for me, as a coauthor, besides acting as consultant, that was the contribution that gave me the greatest pleasure-writing the visualized dialogues, seeing them as a means of helping the user to start interacting, in Brazilian Portuguese.

JMFL: After the launch of the book, did you keep in touch, I mean, besides the meeting in Mexico, what other meetings took place?

FGM: Yes, with Fred and Barrutia. I stayed in touch with Fred, with Barrutia. Barrutia was in São Paulo in 1969, during the PILEI-the Inter-American Linguistic Institute-he came to give a course at USP, where we were teachers. I taught applied linguistics and he taught contrastive linguistics. Fritz and I also met at meetings of PILEI and ALFAL, we have kept on touch because I had more contact with those who were linguists, while Hoge was more a teacher of Portuguese and Brazilian literature. So the relationship with American linguists on the Modern Portuguese writing team was closer and more frequent.

JMFL: So, did you ever discuss the book with them, discuss another edition, another project?

FGM: Yes, but the MLA didn't like the idea because the investment would be high and the market was still too small. It was a hardcover edition, 700 pages, with twenty cassettes, because it also had the recordings. I was the supervisor of the recording of the dialogues and all the exercises. There were sixty hours in 
the main studio of São Paulo to record the contents of Modern Portuguese, and I supervised it. And we had someone to play a character from Pernambuco, we brought someone from Recife because the people we knew in São Paulo were clerks, people who had no free time, or who were not suited to the linguistic task, even to learn to pronounce the sentences in a natural way would have been too much work for them. So we had to choose, there was a problem in the work of recording at the laboratory of Rádio Eldorado in São Paulo: there were twenty huge rolls of audio tape, the result of sixty hours of use of the best studio in Brazil at that time. This part was also my responsibility and for this Yázigi gave its full support, gave everything needed for us to do it.

JMFL: Yes, so although you talked about a new edition, the continuity of the project, the MLA did not approve it due to the cost?

FGM: Yes, because there wasn't enough money for it. It wasn't the practice of the MLA to publish revised, expanded editions, and it hoped that there would be an adoption, that there would be the testing of 1967 through 1969. In 1970 the book was edited and transformed into an edition to be submitted to the publishing houses. MLA thought it had played its part, and that it was the role of the group or those who were in the United States to do the promotion of the book.

JMFL: And was this done?

FGM: It was, I think in a way. And at one stage, in 1971, right when it was launched, the idea of communicative competence was beginning to be discussed. Dell Hymes was the one who said this at that time. But a possible influence of communicative competence was seen in the book. But I think that Modern Portuguese is eclectic, it was an eclectic creation, which enabled the teacher to emphasize this point or that point, and I had the rare joy of using the book many years later when I was a Fulbright Visiting Professor at the University of Georgia, in 1985-1986, so they gave me the group that was called "Beginning Portuguese," a class of students who had done the beginners' course in Spanish. I had one semester of experience using Modern Portuguese in the classroom, for the first time in my life. 
JMFL: And what was this experience like?

FGM: It was interesting, with lots of challenges, because you had a group of students, some were beginners in Spanish, others had little or no knowledge of Portuguese, and others were already thinking of going to Brazil. So you had multiple motivations and multiple competences, and so I used the material for one semester. There was a language laboratory; they went to the language laboratory, I managed to motivate them to be more exposed to spoken language. I found out which students were more motivated, as their motivations were different. There I saw that the book was really adaptable to various interests and students. Most of all, I used it in a new context in 1985, when functionality was more expected. The students asked for additional material, particularly cultural information. They wanted more engagement, to be challenged more, so I created cultural activities that would engage and motivate them, and I used Brazilian music, too. I remember that in 1985 we still didn't have a computer in the classroom. The use of this technology was still in its early days. In any case, this experience was unforgettable, there I was co-author in action, feeling what to select, what to emphasize in each unit so that I could respond to the students' anxieties. It was an incredible experience.

JMFL: Before closing our conversation, I'd like to ask your opinion of PFL in the United States. The people whose works I had the opportunity to read, people who wrote about what could be called the history of this teaching in that country, say that this is a practice like many others, marked by highs and lows. What do you have to say about that? Before the book, and after the book?

FGM: Before the book, you have the role of the official American institutions, for example, the FSI, which trained and still trains personnel, diplomats, in Portuguese. The interesting thing is that some renowned linguists of SpanishAmerican linguistics, based in the United States, worked at the FSI. And they still give this training. Also the pioneering of Spoken Portuguese (one of the volumes in the Spoken Language Series) during the war years, and the support of universities like Georgetown, which funded a book through its university 
publishing house. Wisconsin did the same with Hoge. Some American universities supported the teaching initiative and provided the publication of specific books. Hoge's book was not a commercial edition, finished and so on. But, in a way, it represented the American contribution of the time and helped convince the MLA when Fred designed the proposal. There were the universities that invested in PFL, in the production of materials. Nowadays, things are more diverse. I think there is creativity, productivity in this area. The results are significant. If you consider that there were materials created in New Mexico, in the form of a soap opera, the material called Travessia, which consisted of a soap opera and ambitiously aimed at covering both Brazilian and European Portuguese. There are materials using more advanced, more sophisticated technology, like that of Rosangela Silva, for example, entitled Beginning Portuguese, produced at Arizona State University with CDs for self-learning, together with materials for autonomous learning which are available on the Internet. It's very interesting. I think there is an atmosphere in which Portuguese has sustainability, despite the fact that in some universities it is still linked to a Spanish and Portuguese department. Who knows maybe one day we will have departments only for Portuguese, with sectors dedicated to the Portuguese language. For this it is necessary to prepare, get people interested. And symposiums, meetings that are being held in the United States have a very important role, so that teachers of Portuguese know what is being done and what they can do, in a collective way. I think there is a great need to work as a team, given the specialty and the areas worth exploring today. You have not only linguistic and intercultural knowledge, but also the knowledge of the cognitive dimensions and of the newer, what I call humanizing dimensions, these can also be used in the production of these materials nowadays, in a world that says it wants to be interdependent. Our aim is not only to teach the language well but also to promote the common good. If this second challenge, which is complementary to the first, were considered, this would revolutionize both the curriculum design and the production of materials. Also noteworthy is the role of the associations of Portuguese teachers, our SIPLE, the American Association of Teachers of Spanish and Portuguese. They promote Portuguese; they already give it a certain visibility. And, of course, the government also plays its part, and in 
this respect, the CELPE-Bras examination is being applied in some American universities. It can be a resource for attracting and motivating a new clientele. I know, for example, that Monica Rector of the University of North Carolina has already published Working Portuguese for Beginners, a textbook of Portuguese for commercial or business purposes, so the time is ripe not for general books, but for specific books, that meet more specific needs. Let's do our best to help PLE thrive in the U.S. and globally, too. Yes, Portuguese is becoming an international language.

\section{Note}

1 Derived from post-doctoral research, with the support of CAPES, during the 2010/2011 academic year at the University of Texas at Austin.

José Marcelo Freitas de Luna has a doctorate in linguistics from the University of São Paulo and a postdoctoral degree from the University of Texas at Austin. He is a professor in the master's and doctorate program in education at the University of Vale do Itajaí-Santa Catarina, with research focused on applied linguistics and the historiography of language teaching. His principal publications include O Português na Escola Alemã de Blumenau: da formação à extinção de uma prática (2000), Educação e Lingüística-Ensino de Línguas (2007), and Ensino de Português nos Estados Unidos (2012). 